\title{
El capital social y el incremento en la oferta de cursos de idiomas en la Universidad de Costa Rica: experiencias del curso Catalán Básico I
}

\author{
Edgar Eduardo Blanco Obando \\ Centro de Investigaciones Históricas de América Central (CIHAC) \\ Universidad de Costa Rica
}

\begin{abstract}
Resumen
Este artículo presenta la apertura del curso Catalán Básico I en la Escuela de Lenguas Modernas (ELM) de la Universidad de Costa Rica (UCR), como resultado del capital social generado dentro de la misma Universidad. A su vez, propone crear espacios y fomentar la participación solidaria de los universitarios para obtener mayores proyectos de beneficio público y bien común.
\end{abstract}

Palabras claves: solidaridad, colaboración, bien común, trabajo voluntario, enseñanza, lenguas extranjeras

\begin{abstract}
This article presents the course Catalan Basic I of the School of Modern Languages at the University of Costa Rica, as a result of university's social capital. At the same time, it aims to promote academic's voluntary work to increase projects of common good.
\end{abstract}

Key words: common good, solidarity, cooperation, volunteer work, teaching, foreign languages 


\section{Introducción}

L a enseñanza de los idiomas es importante para fomentar la cultura, la tolerancia y el intelecto entre los estudiantes universitarios, lo cual es un elemento central dentro de la formación profesional y académica que se brinda en la Universidad de Costa Rica (UCR). En esta labor, la Escuela de Lenguas Modernas (ELM) desempeña el papel principal al encargarse de ofrecer una sustanciosa oferta de cursos de idiomas extranjeros a modo de cursos de servicio, que permiten al estudiantado adquirir conocimientos lingüísticos y culturales diversos, además de disponer de espacios donde los alumnos de las diferentes carreras pueden interactuar, intercambiar información, experiencias y conocimientos de interés.

Para asegurar una creciente oferta de cursos de servicio por parte de la ELM, es importante fomentar la colaboración de académicos de modo que aporten sus conocimientos en idiomas extranjeros; para lograr este fin, no es indispensable contar con tiempos docentes o retribuciones económicas que usualmente escasean, sino que puede aprovecharse el capital social generado dentro de la Universidad.

El capital social es una cualidad de los grupos que hace posible la cooperación y la coordinación que facilitan el trabajo por el beneficio mutuo, junto a la construcción de instituciones robustas y representativas (Putnam, 2004).

La Universidad de Costa Rica es una institución pública, financiada con recursos y esfuerzos del pueblo costarricense, y comprometida con la búsqueda del bienestar general de la nación. Según se especifica en su Estatuto Orgánico, la UCR apoya el bien común mediante el fomento de los valores solidarios y humanistas, al igual que el respeto de la institucionalidad, la inclusión, el bienestar público y la justicia social (UCR, 1974).

El compromiso de la institución con el trabajo solidario y el bien común se aprecia en el funcionamiento de un amplio sistema de becas estudiantiles, en el bajo costo de la matrícula, en el fomento del trabajo voluntario desde los proyectos de Trabajo Comunal Universitario (TCU), en la promoción de la discusión crítica y reflexiva, en la enseñanza de las humanidades como base de la formación académica, en la búsqueda de la justicia social y la transmisión de recursos universitarios a la población nacional, especialmente a los colectivos más necesitados y vulnerables, por medio de los programas de acción social y extensión docente.

De esta forma, los valores e ideales solidarios de la Universidad están insertos en el proceso formativo de los estudiantes y en las funciones del personal docente y administrativo. La presencia y fomento de estos elementos forman la base compositiva del capital social generado en la UCR, el cual puede aprovecharse para alcanzar mayor trabajo voluntario de los académicos que permita la apertura de cursos de idiomas, con el fin de incrementar la oferta de la ELM en beneficio de la comunidad estudiantil en específico y de la Universidad en general.

\section{Capital social}

El capital social es resultado de la organización de los grupos orientada a la obtención del bien común mediante la cooperación, con base en el fomento 
de la integración social, la confianza en los otros y en las instituciones, junto con la promoción de valores compartidos que sustenten el trabajo solidario. Así, el capital social es el conjunto de normas y valores que comparten los miembros de un grupo social, que les permite desarrollar relaciones y acciones de cooperación con miras a que priven siempre la confianza y los intereses del bien común (Requena, 2004).

De este modo, el capital social está basado en las redes de interacción, la confianza y las normas, que son los elementos posibilitadores de la cooperación y la coordinación que llevan al beneficio mutuo y a la construcción de instituciones sociales sólidas y representativas (Putnam et al., 1993). Así, el capital social promueve entre las personas el desarrollo de redes de cooperación y el crecimiento de la confianza, lo que provoca que los deseos de colaborar se refuercen, se incrementen y se expandan entre los individuos.

Los sujetos al recibir cooperación de sus semejantes obtienen mayor motivación para involucrarse en asociaciones y empresas colectivas, impulsados por los buenos resultados que la cooperación ha brindado en sus comunidades (Boix, 2000). La cooperación efectiva incrementa la confianza social y genera mayor cooperación, gracias a la información que se divulga a través de las redes sociales. La solidaridad genera, por lo tanto mayor solidaridad.

Las asociaciones generadoras de capital social son aquellas cuya estructura es de tipo horizontal (no jerarquizadas verticalmente), debido a que en ellas se unen actores con poder y estatus semejantes; al contrario de las asociaciones de tipo vertical (jerarquizadas, como la relación entre un patrón con su obrero), donde se relacionan los individuos en posiciones claramente desiguales, con nexos de jerarquía y dependencia (Boix, 2000). Por lo tanto, es en las asociaciones horizontales donde se generan las normas de reciprocidad de la cooperación y la confianza, que construyen el capital social necesario para sustentar la acción colectiva solidaria y el trabajo por el bien común.

Robert Putnam (2002) enfatiza en dos componentes claves del capital social: el compromiso cívico y la confianza, lo cual se debe a que la interacción de estos elementos permite que las sociedades se organicen para trabajar por el bien colectivo y desarrollen, a su vez, una cultura de cooperación, que es el elemento común que les permite comunicarse y cooperar a las personas.

Esta cultura de cooperación caracteriza a las sociedades poseedoras de elevados niveles de capital social y, por lo tanto, también de confianza social, que son los elementos que promueven las acciones hacia la obligatoriedad y el mutualismo, y hacen que las personas esperen que sus semejantes actúen en concordancia y respeto con las normas dirigidas a mantener el beneficio público en las interacciones cotidianas (Putnam, 2002).

Así, el capital social promueve entre los grupos la construcción de redes de cooperación y comunicación que socializan las normas y la confianza, lo cual impulsa a los individuos a involucrarse y trabajar por el bien común, porque estos confían en que su trabajo dará resultados satisfactorios y de beneficio público. 


\section{La comunidad cívica}

La comunidad cívica se caracteriza por un significativo nivel de solidaridad y de participación ciudadana, juntamente con el predominio en la organización social de relaciones horizontales de reciprocidad y cooperación sobre las verticales de autoridad y dependencia (Putnam, 1993). Esta situación da como resultado una mayor igualdad política entre los ciudadanos, así como el apoyo a las normas de reciprocidad y al trabajo por el bien común.

Las normas de reciprocidad y las redes de compromiso cívico que se infunden dentro de los procesos de socialización son elementos importantes en la creación de confianza y cooperación. Las normas de reciprocidad hacen que se esperen en el tiempo las retribuciones a los favores hechos, mientras que las redes de compromiso cívico funcionan como canales de comunicación y de intercambio entre las personas, por lo que son importantes para solucionar conflictos propios de la acción colectiva y para generar capital social, debido a que aportan elementos para el buen gobierno, para el desarrollo general de las comunidades y para lograr el bien común (Putnam, 2004).

En la comunidad cívica, las personas se tratan con justicia y suelen cumplir las normas y esperar que los demás hagan lo mismo; igualmente, confían en que su gobierno sea exigente con él mismo y fomente el cumplimiento de las normas impuestas. Por el contrario, una comunidad menos cívica se sustenta en estructuras jerárquicas y verticales; prevalece entre sus miembros una sensación de explotación y dependencia, la confianza social tiende a escasear y las leyes no son siempre cumplidas, por lo que se afecta negativamente el orden institucional y el funcionamiento del gobierno (Putnam et al., 1993).

Robert Putnam ejemplifica este escenario en su estudio sobre la sociedad italiana, donde afirma que las regiones más cívicas de Italia (en el norte), aquellas donde los ciudadanos participan continuamente en asociaciones cívicas y de voluntariado, en la deliberación colectiva sobre opciones públicas y en la construcción de políticas públicas más efectivas, son también algunas de las ciudades y los municipios más cívicos de la península (Putnam et al., 1993); mientras que el caso contrario acontece en aquellas zonas (al sur) donde la poca participación de los ciudadanos en asociaciones culturales y sociales influye directamente en los pocos niveles de civismo mostrado.

Algunas regiones italianas, como Emilia-Romagna y Toscana, cuentan con numerosas organizaciones comunitarias activas. Lo que llevaba a comprometerse a los ciudadanos de esas regiones eran los asuntos públicos, no el patrocinio. Todos confiaban en que los demás actuarían con justicia y obedecerían la ley. Los dirigentes de esas comunidades son relativamente honrados y se sienten comprometidos con la causa de la igualdad. Las redes sociales y políticas están organizadas horizontal, no jerárquicamente. Estas 'comunidades cívicas' valoran la solidaridad, la participación cívica y la integridad. $\mathrm{Y}$ en ellas funciona la democracia.

En el otro extremo se hallan las regiones 'incívicas', como Calabria y Sicilia, acertadamente caracterizadas por el término francés de incivisme. En ellas el concepto mismo de ciudadanía es 
una noción atrofiada. La participación en asociaciones sociales y culturales es exigua. Desde el punto de vista de los habitantes, los asuntos públicos son cosa de otros — de los notabili, los jefes políticos-, pero no suya. Casi todos están de acuerdo en que las leyes están hechas para ser violadas, pero al temer a la ilegalidad de los demás, todos exigen una disciplina más rigurosa. Atrapados en estos círculos viciosos entrelazados, casi todos se sienten impotentes, explotados e infelices. Apenas sorprende que el gobierno representativo sea aquí menos eficaz que en comunidades más cívicas". (Putnam, 2002: pp.467-468)

\section{El capital social y la acción colectiva}

En toda sociedad existen problemas y desacuerdos entre los individuos a la hora de concertar y cooperar para el logro de metas y proyectos, también es usual que las personas de manera racional busquen la forma de eludir sus responsabilidades y dejarlas a los demás. Estas situaciones dificultan la cooperación y menguan la confianza social, debido a que los sujetos antes de colaborar desconfían de que sus semejantes sean capaces de actuar de la misma manera, lo que afecta directamente el funcionamiento de las instituciones sociales al igual que la relación entre las personas.

De acuerdo con Putnam et al. (1993), estos dilemas de la acción colectiva se controlan con el fomento del compromiso hacia el beneficio común, mediante la socialización de información precisa a través de las redes sociales sobre la buena reputación de las personas y el cumplimiento fiable de las obligaciones. Por lo tanto, la generación de capital social reduce las dificultades y las problemáticas propias de la acción colectiva en las comunidades, porque cuanta mayor confianza exista entre los individuos, se incrementan las posibilidades de cooperar y se tendrá la seguridad de que los demás también lo harán, debido a que la confianza se extiende a lo largo de las redes sociales a modo de información, donde las reputaciones de las personas pasan a ser vox pópuli.

De este modo, existe una estrecha relación entre el capital social y el éxito de la acción colectiva dirigida al alcance del bien común, esto porque las normas y las redes de compromiso cívico son catalogadas como una verdadera precondición para lograr dicho fin (Putnam y Helliwell, 1999). Para Jan Flora (1998), la acción colectiva tiende a dirigirse comprometidamente hacia el bien público en aquellas comunidades con una desarrollada infraestructura social, donde predominan las relaciones sociales de tipo horizontal que promueven la convivencia armoniosa de ideas y valores, a la vez que permiten la fluidez de la información entre los grupos sociales.

Cornelia Butler Flora (1995) sostiene que aquellas comunidades con altos niveles de capital social poseen mayores habilidades y recursos para lograr la solución de sus problemas, al demostrar que la acción conjunta de los sectores sociales permite el logro de los objetivos comunales.

Para Fukuyama (1995), el nivel de confianza de las sociedades es lo que condiciona aspectos claves para su desarrollo, como la prosperidad, el grado de democracia y los niveles de competitividad. Este autor define la confianza 
como componente importante para la medición del capital social, el cual especifica como las normas y valores compartidos, promotores de la cooperación, que permiten en conjunto con otros recursos físicos, financieros y del conocimiento, lograr objetivos y alcanzar metas colectivas.

De esta manera, la confianza es un aspecto clave para fomentar la cooperación que, según Fukuyama, se acumula mediante las normas de reciprocidad y el éxito cooperativo dentro de las redes sociales y de compromiso cívico, donde se difunde la información y se promueve una cultura de cooperación que dirige el actuar solidario de la acción colectiva.

\section{UCR como entidad generadora de capital social}

De manera específica, según lo estipulado en el Estatuto Orgánico de la Universidad de Costa Rica, la entidad se define como:

una institución de educación superior y cultura, autónoma constitucionalmente y democrática, constituida por una comunidad de profesores y profesoras, estudiantes, funcionarias y funcionarios administrativos, dedicada a la enseñanza, la investigación, la acción social, el estudio, la meditación, la creación artística y la difusión del conocimiento. (UCR, 1974: 1)

El accionar de la institución se dirige a contribuir en la transformación de la sociedad para lograr el bien común a partir de la ejecución de acciones hacia la justicia social, la equidad, el desarrollo, la libertad y la independencia de la población nacional; esto mediante el sustento de una acción universitaria planificada que contribuye al incremento del desarrollo humano y la calidad de vida de las personas (UCR, 1974).

El cumplimiento de las acciones universitarias para el fomento de la cooperación y el logro del bien común se evidencia en la actividad de la Vicerrectoría de Acción Social (VAS), que facilita los recursos y espacios para que académicos, funcionarios y estudiantes elaboren y participen en programas dirigidos a promover el desarrollo social mediante el fomento de la cooperación y la coordinación para la promoción de capacidades sociales, así como la solución misma de muchas de las necesidades de la población nacional (VAS, 2016).

Para el 2016, se reportaron en vigencia en la VAS alrededor de 600 programas inscritos en las modalidades de Trabajo Comunal Universitario, Extensión Docente y Extensión Cultural, pertenecientes a las diferentes áreas del saber académico y con influencia en todo el país (VAS, 2016).

De esta forma, se evidencia que el quehacer de la UCR se sustenta en normas y valores solidarios que fomentan la cooperación y el logro del bien común. A su vez, sostiene procesos de socialización dentro de una cultura de colaboración y confianza que sirve de base a la acción colectiva y al fomento de deseos de colaborar y trabajar por el bienestar social. 


\section{Surgimiento del curso Catalán Básico I}

El curso LM-7038 Catalán Básico I se abre como curso de servicio de la ELM en el primer semestre de 2014, como resultado del apoyo del personal de la Escuela al trabajo solidario de un docente formado en la UCR, conocedor con nivel avanzado de la lengua catalana e interesado en enseñar el idioma en la Universidad.

Así, desde los deseos de colaborar del docente se hizo posible por primera vez en la historia de la UCR la apertura de un curso de lengua catalana, el cual ha tenido una aceptación relevante por parte de la comunidad estudiantil. Desde su apertura en marzo de 2014, el curso se ha ofrecido cada semestre con una matrícula inicial no menor a 25 estudiantes.

Esta significativa matrícula evidencia que el curso ha venido a satisfacer una necesidad latente entre los estudiantes de conocer elementos propios de la lengua y la cultura catalanas, la cual se ha podido satisfacer gracias a los deseos de cooperación y al trabajo solidario por el beneficio colectivo.

De este modo, el trabajo académico solidario ha logrado incrementar la oferta de cursos de servicio de la ELM, al brindar mayores oportunidades de crecimiento intelectual y cultural para los estudiantes y al aportar al dinámico funcionamiento de la Universidad.

\section{Conclusiones}

El curso Catalán Básico I es resultado del capital social generado dentro de la UCR, que ha permitido, desde el trabajo voluntario y colaborativo, el incremento de la oferta de cursos de lenguas para el beneficio de la comunidad estudiantil de la misma Universidad.

La UCR es una entidad solidaria generadora de capital social, con gran influencia socializadora en un gran número de estudiantes, funcionarios $\mathrm{y}$ docentes; por esta razón, es importante abrir espacios y fomentar el trabajo solidario para construir mayores proyectos de beneficio social.

\section{Bibliografía}

Boix, Carles. Per a fer que la democràcia funcioni. La importància del capital social. Barcelona: Centre d' Estudis de Temes Contemporanis, 2000.

Flora, Cornelia Bulter. Social Capital and Sustainability: Agriculture and Communities in the Great Plains and Corn Belt. Research in Rural Sociology and Development: A Research Annual, 6 (1995): pp.227-246.

Flora, Jan. Social capital and communities of place. Rural Sociology, 63, 4 (1998), pp.481-506.

Fukuyama, Francis. Trust: The Social Values and the Creation of Prosperity. New York: Free Press, 1995.

Putnam, Robert D., Leonardi, Robert y Nanetti, Raffaella. Making Democracy Work: Civic Traditions in Modern Italy. Nueva Jersey: Princeton University Press.

Putnam, Robert D., Helliwell, John F. Education and Social Capital. Working Paper 7121. Massachusetts: National Bureau of Economic Research, 1999.

Putnam, Robert D. (editor). Democracies in Flux. The Evolution of Social Capital in Contemporary Society. Nueva York: Oxford University Press, 2002. 
Putnam, Robert D. Solo en la bolera. Universidad de Costa Rica. Estatuto OrColapso y resurgimiento de la comunidad norteamericana. Barcelona: Galaxia Gutenberg, Círculo de Lectores, 2004.

Requena, Félix. El capital social en la Encuesta de Calidad de Vida en el Trabajo. Papers N. ${ }^{\circ}$ 73, pp.11-26. Barcelona: Universidad Autónoma de Barcelona, 2004. gánico de la Universidad de Costa Rica. San José: UCR, 1974.

Vicerrectoría de Acción Social (2016). Portal de Acción Social. www.accionsocial.ucr.ac.cr

Woolcock, Michael. Social Capital in Theory and Practice: Where Do We Stand? Washington: Development Research Group, The World Bank, 2000. 